\title{
Capacidades institucionales del gobierno municipal en el diseño y gestión de políticas habitacionales
}

\section{Local government institutional capacities in the design and management of housing policies}

\author{
Daniela Mariana Gargantini* \\ Carolina InÉs Pedrotti**
}

\begin{abstract}
The participation of the municipality in the implementation of different urbanhousing decisions is strategic in the design and management of more relevant policies. This involvement is restricted not only by the policy design conditions, but also by the available municipal capacities.

This paper analyzes the involvement of municipalities in the definition, design, and implementation of housing policies, taking as an example two case studies (one Mexican and one Argentinian) with distinct characteristics.

The interest lies in identifying the existing and necessary to develop institutional capacities, as a privileged strategy for the improvement of existing housing policies.
\end{abstract}

Keywords: Housing policies, municipalities, institutional capacities

\section{Resumen}

La participación del municipio en la implementación de las distintas decisiones urbano-habitacionales resulta estratégica en el diseño y gestión de políticas más pertinentes. Este involucramiento se encuentra restringido no sólo por las condiciones de diseño de la política, sino también por las capacidades municipales disponibles.

Este trabajo analiza el involucramiento de los municipios en la definición, diseño e implementación de las políticas habitacionales, tomando como recursoejemplo el estudio de dos casos (uno mexicano y otro argentino) con características diferenciadas.

El interés radica en identificar las capacidades institucionales existentes y necesarias de desarrollar como estrategia privilegiada para el mejoramiento de las políticas habitacionales vigentes.

Palabras clave: políticas habitacionales, municipios, capacidades institucionales. 


\section{Introducción}

La cuestión habitacional en América Latina es uno de los factores de mayor incidencia en la determinación de la pobreza. Si bien en los últimos años el acceso a la infraestructura y los servicios ha mejorado en la región (Blanco, 2016; Cepal-NU, 2016), y el desarrollo habitacional ha generado impactos relevantes en las ciudades (en términos de producción de prototipos, incremento de la oferta, dinamización de la industria de la construcción y los mercados financieros asociados), es evidente también que desde hace ya varias décadas los indicadores habitacionales no han variado sustancialmente, y los problemas estructurales — de orden más cualitativo e integral- persisten. ${ }^{1}$

En este sentido, aunque los programas de mejoramiento y de participación activa del usuario se hayan incrementado en las últimas décadas, las políticas implementadas han mantenido su enfoque, mayoritariamente, en modelos de producción de vivienda terminada, producida centralizadamente por empresas inmobiliarias y con escasa participación de las familias destinatarias. ${ }^{2}$

Concomitantemente con ello, desde la década de los noventa, los procesos de descentralización política y administrativa han contribuido a renovar el papel específico de las ciudades; el protagonismo de los ámbitos locales se ha acrecentado y se ha planteado la necesidad de impulsar modificaciones en sus modos de gestión, reforzar sus capacidades financieras y técnicas, así como favorecer las asociaciones público-privadas y la participación de la sociedad civil y articulación entre los distintos niveles de gobierno (Cepal-Minurvi-NU, 2016).

\footnotetext{
${ }^{1}$ En Argentina, según datos del último Censo Nacional (Indec, 2010), 28.4\% de los hogares del país $(3,450,860$ hogares) padecen situaciones deficitarias por precariedad o hacinamiento. De ellos, $62.3 \%$ resolvería sus problemas mediante ampliación, refacción o completamiento, mientras que sólo 37.7\% necesitan una vivienda nueva. Por su parte, datos del BID (2012) indican que México contaba en 2011 con un déficit cuantitativo de $2 \%$ de sus hogares (563,187 hogares), mientras que los déficits cualitativos representaban porcentajes mayores en todos los casos (calidad de materiales 9\%; hacinamiento 5\%; inseguridad de la tenencia $15 \%$, infraestructura precaria $8 \%$ ).

${ }^{2}$ Argentina: en el periodo 2002-2010, 68.7\% de las soluciones brindadas en el país fueron viviendas nuevas. Sólo $31.3 \%$ de lo producido tuvo otro tipo de soluciones (lotes y servicios, núcleos húmedos, terminaciones y ampliaciones). Similares datos se registran en 2014, donde se construyeron 24,724 viviendas y sólo 11,317 de otras soluciones habitacionales bajo los programas federales. (CNV, 2017).

México: en lo que respecta al financiamiento a la vivienda, de 1993 a 2002, 47\% de los fondos fueron destinados a la vivienda terminada, mientras que los financiamientos para acciones de pie de casa o lotes con servicios no representaron más que 5.5\%, y los mejoramientos no superaron 30\% (Coulomb, 2010: 571). Entre 2001 y 2006, los programas de vivienda completa representaron 60\% del total de financiamientos, y de 2007 a 2011 descendieron a 51.1\%. Otros apoyos, como los financiamientos para vivienda inicial, tuvieron una participación del $5 \%$, o los de infraestructura $0.6 \%$ (UNAM, 2013: 15, 39-40).
} 
Los gobiernos municipales se han visto interpelados a asumir actitudes activas orientadas a la gestión de políticas sociales y urbanas en el marco de procesos de desarrollo local y regional.

Los procesos, de los cuales la dimensión habitacional forma parte, "han cobrado así fuerza como complemento necesario del proceso de globalización y como principio esencial del desarrollo sustentable, al reducir la escala de manejo de los problemas y favorecer la participación y el desarrollo de procesos endógenos" (González Couret et al., 2011: 170).

Sin embargo, ante la recuperación del papel de los estados nacionales y el surgimiento de gobiernos "post-neoliberales", tras la crisis capitalista iniciada en 2008, la tendencia mencionada se ha refrenado; en la última década se registraron procesos recentralizadores en materia de diseño y gestión de políticas sociales (Cravacuore, 2015). Las acciones en materia urbana y habitacional no han permanecido ajenas a dichos procesos, ya que se han reducido las posibilidades de diseñar y gestionar políticas urbanohabitacionales más adecuadas a las necesidades reales de la población.

Ahora bien, la reversión de este proceso decentralizador encuentra sus posibilidades de atención y resolución no sólo en el impulso de políticas que incluyan a los municipios como sujetos activos en su gestión e implementación, sino en estrecha relación con las capacidades institucionales del gobierno municipal, en cuanto sujeto factible de recuperar el rol que le compete en temáticas de indiscutible incumbencia local, como resulta la planificación y gestión del territorio, y con ello, el hábitat de los ciudadanos (Cepal-Minurvi-NU, 2016).

Desde una visión más amplia, hablar de capacidades institucionales implica la recuperación del rol del Estado en las propuestas de desarrollo y supone referirse a la asunción de responsabilidades por parte del mismo: a la toma de decisiones frente a distintos asuntos y problemas públicos y a la existencia de habilidades para resolverlos. Rosas Huerta (2008: 120) las describe como "la habilidad de las instancias gubernamentales para mejorar las funciones y resolver problemas públicos, así como la capacidad que tienen para movilizar o adaptar sus instituciones para dar respuesta a dichos problemas".

En materia de políticas sociales - como concebimos a las políticas urbanas y habitacionales-, la generación y fortalecimiento de capacidades institucionales resulta elemental y pertinente para los ámbitos locales de gobierno; estas habilidades deben ser entendidas tanto a nivel directivo como técnico, en tanto que los municipios son capaces de desempeñar las tareas propias de manera eficaz, eficiente y sostenida (Castillo Blanco, 2004 y Hilderbrand y Grindle, 1997).

Asimismo, resultan determinantes del tipo y alcance de las intervenciones posibles, "son el resultado final de inversiones que toman lugar a 
través del tiempo [...] y de decisiones endógenas tomadas por actores políticos claves" (Scartascini y Tommassi, 2014: 6 y 15; Alonso, 2007). De igual forma, constituyen las bases para el replanteamiento de nuevos modos de definición de políticas públicas con mayor participación del nivel local en su determinación y ejecución.

La presente investigación analiza las potencialidades del involucramiento y participación del ámbito municipal de gobierno en las políticas habitacionales, tanto en la fase de definición (diseño) como de su implementación (gestión), para ello se desarrolla un marco conceptual sobre capacidades institucionales en el ámbito local, seguido de una propuesta metodológica para su análisis en relación con las políticas habitacionales.

En segundo lugar, dicha propuesta es contrastada e ilustrada tomando como insumo dos casos, lo que habilita una lectura reflexiva de las variables e indicadores que se contemplan; la selección de los casos considera recursos-ejemplos en los que el rol del gobierno municipal y sus capacidades institucionales relacionadas con la problemática habitacional presentan un comportamiento diferente: gestión de la producción de conjuntos urbanos en municipios del Estado de México, México, y programa de apoyo a la gestión local del hábitat en municipios de ciudades pequeñas e intermedias de Argentina.

Cabe aclarar que si bien los casos analizados responden a iniciativas impulsadas por ámbitos de gobierno supramunicipales no resultan estrictamente comparables, dado que responden a experiencias de naturaleza y alcance diverso, no sólo en términos territoriales sino en cuanto al nivel de producción alcanzado por cada uno.

El caso mexicano se focaliza en la producción de conjuntos urbanos - grandes conjuntos habitacionales- en municipios del Estado de México; éste se enmarca en una política habitacional de diseño centralizado (nacional/federal) y de gestión desde el ámbito de gobierno intermedio (estatal) con amplia aplicación a lo largo del país, en la cual el Estado de México resultó ser un ejemplo paradigmático. Tuvo como motivación principal atender el déficit desde la producción industrial y masiva de vivienda por agentes privados y estuvo caracterizado por cuotas de participación de los municipios muy limitada.

El caso argentino resulta una iniciativa puntual y de alcance "piloto", caracterizada por el interés de visibilizar a los municipios y posicionarlos a partir del fortalecimiento de sus capacidades, con el objeto de que luego se conduzcan, con herramientas más certeras, a soluciones habitacionales en sus jurisdicciones. El programa focalizó su acción en el fortalecimiento institucional, previo a la formulación de políticas habitacionales, pero no tuvo producción de viviendas asociada directamente hasta la 
fecha; de esta manera, su desarrollo resulta un insumo para el rediseño de políticas habitacionales vigentes en el país.

Los alcances de los casos seleccionados son diferentes, ${ }^{3}$ sin embargo, su carácter ejemplificador resulta útil en el abordaje analítico-propositivo de este artículo, cuyo interés y aporte se basa en el análisis de los procesos de consideración, capitalización y fortalecimiento de las capacidades de los gobiernos municipales que la implementación de dichos casos ha promovido.

Más allá, el análisis efectuado resulta un insumo para la identificación de las condiciones institucionales y capacidades locales existentes (pero especialmente necesarias de desarrollar o capitalizar), así como de los alcances y limitaciones del ámbito municipal de gobierno en la atención de las diversas problemáticas habitacionales. Se intenta contribuir en la identificación y proposición de estrategias de mejoramiento de las políticas habitacionales vigentes.

\section{Políticas habitacionales, rol del gobierno local y capacidades institucionales}

La política habitacional resulta un componente elemental de la política urbana porque su orientación y ejecución es relevante en tanto puede -nada menos- aportar al orden o al desorden urbano con distintas consecuencias espaciales, sociales y ambientales.

Puede visualizarse como una relación articulada "de ida y vuelta" porque la naturaleza de la vivienda requiere vincularse con otros bienes y servicios de la ciudad para su adecuado funcionamiento y, a su vez, los espacios habitacionales "inciden de manera decisiva en la conformación de la estructura urbana" (Schteingart, 1989: 9).

Bajo esta premisa inicial, y asumiendo que para su concreción se requiere de la coordinación entre diferentes ámbitos de gobierno, así como de cuantiosos recursos que por su envergadura generalmente provienen del ámbito nacional o provincial-estatal, se afirma que las políticas urbanas y las acciones que de éstas se derivan se encuentran estrechamente vinculadas al gobierno local o municipal, ya que justamente éste es quien por su condición de cercanía tiene la posibilidad de conocer con mayor detalle y pertinencia la naturaleza y alcance de las situaciones a resolver,

\footnotetext{
${ }^{3}$ No se pretende generalizar y con ello presentar a los municipios mexicanos o argentinos como un ente homogéneo; aun con el reconocimiento de características diferenciadas (en escala, complejidades territoriales y tamaños de población) es posible señalar que en ambos contextos las autoridades de gobierno municipal se han enfrentado a la resolución de la problemática habitacional con similares marcos institucionales, niveles de (des)conocimiento, especialización de sus recursos humanos y condiciones de dependencia, decisoria y financiera de ámbitos de gobierno superiores.
} 
además de que cuenta entre sus competencias centrales con la facultad de intervenir de manera directa sobre los asuntos urbanos que afectan su ámbito territorial. ${ }^{4}$

A pesar del proceso de revalorización de lo local como ámbito emergente en la década de los noventa del siglo pasado, tras el mencionado proceso recentralizador post 2008, persiste por parte de los ámbitos centrales de gobierno la asignación real de un rol secundario, despolitizado, marginal, meramente operativo o ejecutor de políticas diseñadas en niveles superiores, sin mayor capacidad de incidencia para el gobierno local (Brugué y Gomà, 1998).

Por otra parte, amén de los procesos recentralizadores alentados en la última década desde distintos movimientos internacionales, que resultan referentes en la temática, continúa creciendo la conciencia "de que el modelo de producción actual ha encontrado sus límites [...] y en ese contexto los gobiernos locales y regionales necesitarán situarse en el centro de las políticas públicas, para dar a los ideales formas políticas concretas, transformándolos en realizaciones prácticas que hagan de los asentamientos humanos el principal vector para avanzar hacia una era más sostenible"; tan es así que compromisos de alcances globales han comenzado a promover y reclamar fuertemente que "los gobiernos locales y regionales ahora desempeñen un papel creciente en la regulación del desarrollo urbano y territorial y en la protección de los bienes comunes", comprometiendo una serie de acciones para su consecución (UCLGCGLU, 2016; Global Taskforce, 2016 y Naciones Unidas, 2016).

Este posicionamiento encuentra ya su aval en las estipulaciones de los marcos normativos en distintos países (específicamente los dos analizados en esta investigación), donde las atribuciones municipales sobre desarrollo urbano incluyen la formulación y ejecución de instrumentos de planeación del territorio, algunas acciones en la gestión del suelo (autorizaciones y cambios de uso, licencias de construcción, etcétera), la supervisión de obras y construcciones, la gestión de los distintos servicios públicos urbanos, entre otros.

Explícitamente, refiriéndonos a la producción habitacional, la experiencia indica que el rol de los gobiernos locales en la fase de formulación de las políticas que la promueven es prácticamente nulo, si no marginal. Esto es reflejo de la desconfianza que los ámbitos de gobierno intermedio y central tienen para con los locales y que, según Brugué y Gomá (1998: 16), “... se traduce en limitaciones competenciales, poca generosidad en

\footnotetext{
${ }^{4}$ Es importante resaltar la diferencia entre "funciones" o "incumbencias", las primeras especifican lo que el municipio debe hacer a partir de las demandas y requerimientos de la sociedad, éstas sufren modificaciones en el tiempo; "competencias" son aquéllas que el marco legal le reconoce al municipio como entidad jurídica pública (Villar, 2002).
} 
la transferencia de recursos, proliferación de mecanismos de control y tutela o restricciones legislativas a su capacidad de actuación".

En la fase de implementación y gestión de las políticas mencionadas está presente de manera más visible la labor de los ámbitos de gobiernos intermedios, provinciales en Argentina y estatales en México, y en menor medida los municipales, ya que son éstos quienes en general operan las acciones más concretas que se derivan de los programas y proyectos (Pedrotti, 2016) a través de "la adopción de roles meramente operativos", ejecutores de políticas diseñadas en ámbitos superiores (Brugué y Gomá 1998: 29).

$\mathrm{Al}$ referirse a capacidades institucionales, este artículo estructura el análisis de éstas en los gobiernos municipales a partir de la definición acuñada por Alonso (2007), quien retoma a Hilderbrand y Grindle y formula un aporte simplificador e integrador de las principales variables e indicadores para la medición de capacidades; Alonso afirma que éstas podrían resumirse en dos dimensiones básicas: las capacidades técnicoadministrativas, vinculadas a la existencia de núcleos y patrones de funcionamiento técnico burocráticos; y las capacidades institucionales-políticas, vinculadas a la constitución de los intereses, a las preferencias de los actores y a la fijación de probabilidades de realización de intereses/demandas provenientes de la sociedad.

Para el análisis de capacidades estatales deben considerarse, entonces, dos dimen-
siones: por un lado lo que hace a las capacidades técnico-administrativas y por
otro una dimensión que se refiere a la relación del Estado con el entorno socioe-
conómico. Desde la primera perspectiva, el análisis de capacidades priorizará una
mirada desde adentro del aparato estatal, mientras que la dimensión relacional
pondrá el foco en el nexo estado-sociedad [...] El logro de un equilibrio entre las
lógicas de los dos planos señalados es lo que se ha llamado autonomía enraizada
[denominada por Evans (1996) como embedded] [...] estudiada mediante una
integración de análisis estático y dinámico (Alonso, 2007: 4-5).

Esta postura no se limita a aspectos técnico-administrativos, es decir, "puertas adentro" del aparato estatal, sino que en todo caso pone énfasis en el apartamiento y aislamiento de sus cuadros técnico-burocráticos de los grupos de interés, su entorno y sociedad (Rosas Huerta, 2008: 122).

En este contexto, el concepto que permite aumentar la capacidad es el de construcción de capacidad institucional (capacity building), el cual “asume una visión más compleja y un enfoque de sistemas que ubica los problemas organizacionales dentro de un entorno con varios niveles, actores e influencias, y con importantes interdependencias entre éstos" (Rosas Huerta, 2008: 121). 
Actualmente, la capacidad de las instituciones del sector público está relacionada con la gobernanza (governance), se construye fortaleciendo a la organización a partir de su diversidad, su pluralismo, su autonomía y su interdependencia con relación a otras organizaciones en el sistema. En este sentido, "construir capacidad institucional significa también promover y crear redes de interacción entre las organizaciones del sector público y privado y las organizaciones no gubernamentales" (Rosas Huerta, 2008: 123).

Las dimensiones (capacidades técnico-administrativas e institucionales-políticas) se corresponderían, a la vez, con dos niveles de análisis: el entorno macro-institucional, que atiende al entramado de reglas de juego formales e informales que regulan el accionar de una determinada agencia estatal, o cuya construcción opera como la condición de posibilidad para su funcionamiento de acuerdo a los objetivos establecidos; y el entorno micro y meso-institucional, que atiende a la dimensión de las capacidades individuales y organizacionales necesarias para alcanzar los objetivos prefijados (Alonso, 2007 y Rosas Huerta, 2008).

Esta mirada coincide con lo seńalado por Rosas Huerta (2008: 128), quien afirma que "para evaluar la capacidad institucional se requiere aunar los componentes (subtipos) de dicha capacidad: administrativo y político. Estos subtipos permiten considerar que el estado no sólo es el aparato burocrático, sino también es una arena política en la que se procesan intereses e ideologías tanto internas como externas al entramado organizacional estatal". La autora también acuerda en considerar los niveles de análisis micro y meso en las capacidades administrativas, y el nivel o entorno macro para las capacidades políticas (Rosas Huerta, 2008: 131, 133 y 134).

Así, la instrumentación de variables e indicadores provista por estos autores es complementada para esta investigación con otros aportes relevantes: 1 . Los que derivan de las bases conceptuales del neoinstitucionalismo, que recurre a una consideración positiva de las capacidades relacionada con la eficacia administrativa del aparato estatal para instrumentar sus objetivos oficiales, medida en función de su adecuación o inadecuación respecto de las funciones que debe cumplir (Sikkink, 1993 y 1991); ${ }^{5} 2$. El abordaje provisto por Oszlak y Orellana (2001), que las define desde la consideración de carencia o déficit institucional; ${ }^{6} 3$. El enfoque de Fiszbein (1997) (en Moreno Jaimes, 2007: 134-135) que define la capacidad como un "factor posibilitante" (enabling factor), es decir, como la existencia

\footnotetext{
${ }^{5} \mathrm{Y}$ como habilidad para desempeñar tareas propias de manera efectiva, eficiente y sostenida (Castillo Blanco, 2004; Hilderbrand y Grindle, 1997; Scartascini y Tommassi, 2014)

${ }^{6}$ Este déficit puede definirse como una brecha perceptible entre lo que la tarea implica (v.g. la acción que debe realizarse) y lo que el actor responsable (agencia, individuo, asociación; en este caso el municipio) afirma que hará (Oszlak y Orellana, 2001).
} 
de instrumentos que hacen posible que un gobierno (local en este caso) se desempeñe exitosamente, ${ }^{7}$ y 4 . El abordaje que, específicamente referido al diseño y gestión de las políticas habitacionales, propone tres dimensiones iniciales para estimar las capacidades del gobierno local: a) estructuración del problema y experiencias previas, $b$ ) capacidad de planeación, gestión y recursos disponibles y c) adecuación socio-políticatécnica de las iniciativas (Gargantini et al., 2015). ${ }^{8}$

La tabla 1 evidencia la integración de las distintas propuestas de caracterización y medición de capacidades institucionales desarrolladas. Al respecto, cabe advertir que quienes realizan evaluaciones de la capacidad institucional deben decidir si abordan todas o seleccionan sólo aquellas que pueden ser representativas o claves para una política pública, partiendo del reconocimiento de las limitaciones de recursos (económicos, humanos, de información y de tiempo) a las que se enfrenta una evaluación de esta naturaleza (Rosas Huerta, 2008: 133-134).

Bajo este marco conceptual, el trabajo describe y analiza las capacidades institucionales de los gobiernos locales en el diseño y gestión de políticas habitacionales de dos casos seleccionados; para dicho análisis se recurrió al uso de fuentes primarias y secundarias: $a$ ) consulta documental de distintos instrumentos de política, legislación y normatividad que sustentaron cada una de las experiencias, $b$ ) registros de entrevistas a funcionarios y técnicos, así como de talleres participativos con los equipos técnicos involucrados en las iniciativas y $c$ ) registro de las visitas realizadas a los municipios estudiados. ${ }^{9} \mathrm{El}$ acceso a dichas fuentes permitió operacionalizar las variables y los indicadores escogidos para el análisis.

\footnotetext{
${ }^{7}$ Para el autor estas capacidades pueden clasificarse en tres categorías: mano de obra (profesionalización de los servidores públicos), capital (infraestructura física a disposición del gobierno local) y tecnología (estilo de gestión interna de sus agencias públicas, es decir, sus funciones de gestión, planeación, control y evaluación, así como a la obtención, procesamiento y distribución de la información gubernamental). Ahora bien, la existencia de estos instrumentos no determina su buen uso y aprovechamiento, por lo que este factor posibilitante podría ser entendido como un potencial a desarrollar (un atributo latente, como bien lo seńala Moreno Jaimes), más que un resultado en sí.

${ }^{8}$ La primera dimensión comprende la interpretación de los problemas a atender, la precisión de objetivos y metas, así como decisiones de modalidad constructiva, productiva y financiera que permitirán materializarlos; la segunda considera la planeación y gestión de recursos (temporales, humanos, económicos, de infraestructura) según existencia y disponibilidad a escala municipal; la tercera dimensión considera el nivel de pertinencia y correlación entre las necesidades y capacidades de la población destinataria y las acciones que se desarrollan, tanto a nivel socio-cultural como económico, financiero y ambiental (Gargantini et al., 2015).

${ }^{9}$ Caso mexicano: 1. Documentos institucionales-gubernamentales que constituyen el marco programático y regulatorio de la producción habitacional reciente (Programa Nacional de Vivienda 2001-2006 y 2007-2012; Ley federal de vivienda 2006; Programa Estatal de Desarrollo Urbano del Estado de México 2003; Libro Quinto del Código Administrativo del Estado de México 2001 y su reglamento, versión 2002; Código Financiero del Estado de México); 2. Entrevistas realizadas en 2013 a funcionarios de la administración del desarrollo urbano y la vivienda en el Estado de México (Secretaría de Desarrollo Urbano en sus tres direcciones generales: Operación Urbana, Planeación Urbana y Control Urbano); 3. Consulta de página electrónica de la Secretaría de Desarrollo Urbano
} 


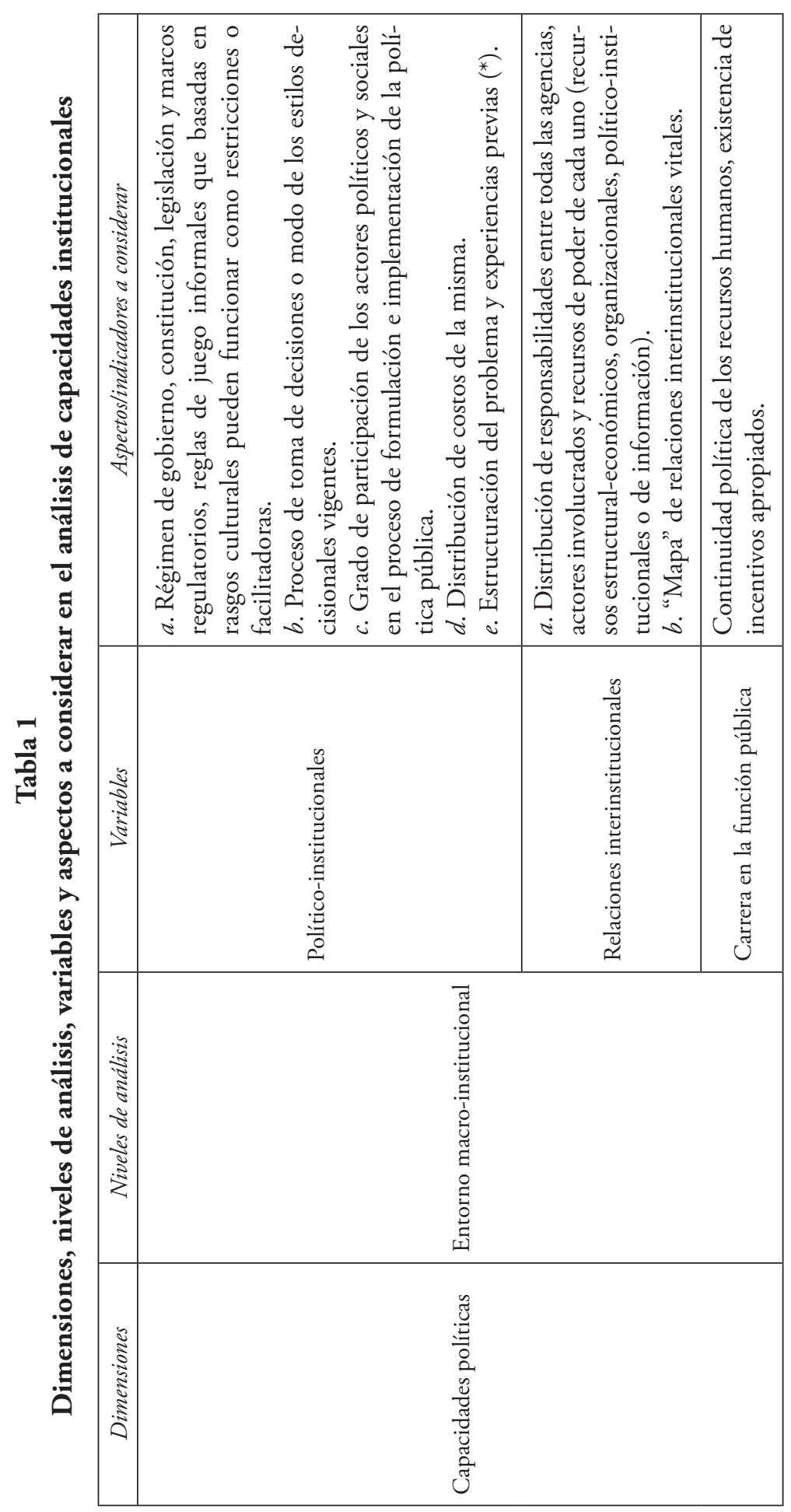




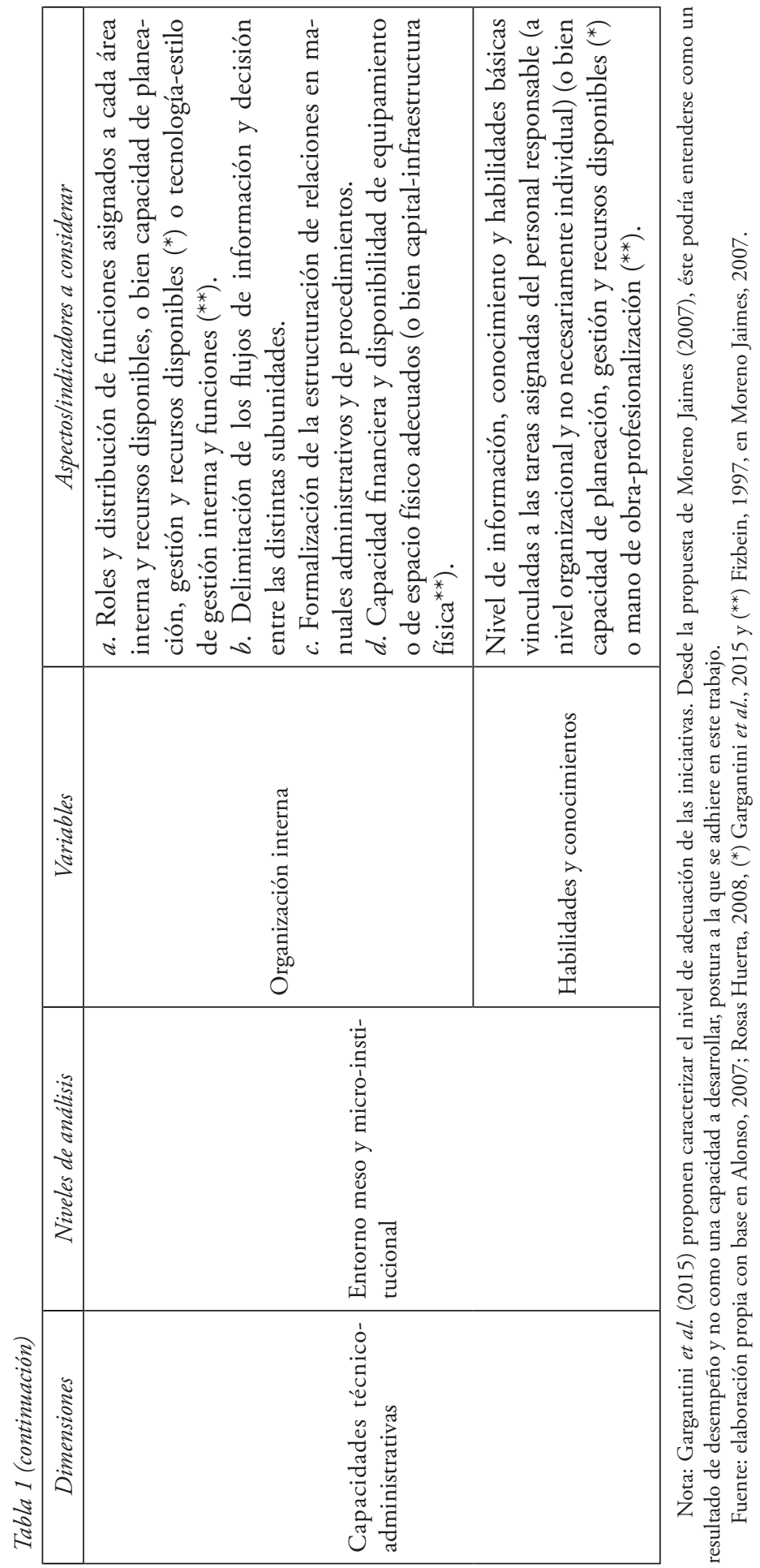




\section{Análisis de las capacidades institucionales locales}

\subsection{El caso mexicano: la gestión de la política habitacional en municipios del Estado de México para la producción de conjuntos urbanos}

En el Estado de México, la gestión de la política habitacional reciente (de mediados de los noventa del siglo pasado a 2012) privilegió la estrategia de producción de conjuntos urbanos como modelo de solución habitacional que pretendía atender a la población joven asalariada de los sectores populares y medios en la entidad mexiquense.

Este caso representa un claro ejemplo de cómo en México, y particularmente en el Estado de México, el enfoque de las acciones destinadas a resolver el problema habitacional (más que una política habitacional o programa de vivienda), 1. Privilegiaron la producción promocional del sector mercantil (empresas "desarrolladoras") a través de la regulación de las dependencias gubernamentales encargadas del ordenamiento territorial y opciones de financiamiento tanto de los Organismos Nacionales de Vivienda (Onavis) como de la banca privada; 2 . Centraron su implementación en el ámbito de gobierno intermedio-estatal y 3. Relegaron en varias cuestiones importantes la acción (participación, decisión y capacidad de ejecución) de los gobiernos municipales.

Al tratarse de una estrategia que se utilizó en todo el territorio mexicano, cabe señalar que el Estado de México representa un caso singular en el

del Gobierno del Estado de México de 2012 a 2014, que incluye especificaciones sobre autorización, seguimiento y municipalización de conjuntos urbanos, así como una base de datos con información sobre conjuntos urbanos autorizados en los municipios del Estado de México (periodo consultado: 1999-2011); 4. estas y otras fuentes citadas en este artículo fueron revisadas en el marco de la elaboración de la tesis doctoral "Calidad residencial y condiciones de producción en la vivienda social promovida por el sector privado. Zona Metropolitana de Toluca, 2001-2011" realizada entre 2011 y 2015 dentro del Programa de Doctorado en Urbanismo de la Universidad Nacional Autónoma de México.

Caso argentino: 1. Censo Nacional de Población y Vivienda 2010. Indec; 2. Base de datos y contactos de gobiernos locales y áreas de vivienda del país 2015- SAM-MI. 3. Programa de apoyo para la Gestión Local de Hábitat, Convenio Específico de Cooperación Institucional firmado entre SAM-MI, Conicet y AVE del 5 de diciembre de 2014, expediente núm. 124678/2014 y resolución 1953/2014; 4. Registros de visitas y de entrevistas a funcionarios, técnicos y comunidades involucradas, entre noviembre del 2014 y diciembre del 2015 en Peñaloza (La Rioja), Laguna Blanca (Chaco), San Isidro (Corrientes), Belén (Catamarca), Tunuyán (Mendoza), Goya (Corrientes); 5. Informes de situación municipal de cada municipio donde se trabajó con el Programa; 6. Propuestas para abordaje local de proyectos integrales del hábitat en cada municipio donde se trabajó con el Programa 7. Presupuestos estimativos para concreción de la propuesta teniendo en cuenta todos los factores relevados, disponibles todos ellos en el Informe final del Programa presentado ante SAM-MI el 6 de enero de 2016; 8. Convenio específico entre SAM-MI, Conicet y AVE para realizar capacitaciones en producción y montaje de sistemas constructivos de patente AVE-CEVE-Conicet, expediente núm. 51179/2015; 9. Fuentes secundarias provenientes de especialistas en el estudio de la evolución de las políticas habitacionales del país tales como Yujnovsky, Rodulfo y Wagner. 
sentido de que, en primer lugar, se refiere al diseño y orientación de los instrumentos de planeación, organización jurídica y operativa respecto de la producción de vivienda y el desarrollo urbano en la entidad mexiquense - destacados a nivel nacional y convertidos incluso en un referente para otros estados de la república-, diseñados ad hoc con las reformas a las políticas habitacionales federales de fin de siglo XX y principios del XXI.

En segundo lugar, el volumen del inventario producido en conjuntos urbanos también es destacable a nivel nacional $;{ }^{10}$ tratándose de la entidad más poblada de México, su dinámica demográfica y de producción de nuevos espacios habitacionales sobresale respecto de otros estados.

\section{Dimensión: capacidades políticas \\ Nivel de análisis: entorno macro-institucional Variable: político-institucionales}

a. Régimen de gobierno, constitución, legislación y marcos regulatorios, reglas de juego informales.

Antecedentes: A partir de 1950, en concurrencia con una etapa de urbanización y desarrollo industrial avanzado en el país, México inició la creación de los principales organismos nacionales de vivienda (Onavis): Fovi, 1963 (hoy SHF); Infonavit y Fovissste, 1972. Estos organismos constituyeron la plataforma del sistema institucional de vivienda basado en un modelo intervencionista de Estado (promoción, construcción, financiamiento con tasas de interés preferenciales y aplicación de subsidios).

La política en estudio: El sistema institucional de vivienda referido se transformó profundamente a partir de la década de 1990, al adoptarse un modelo facilitador que delegó la promoción en el sector privado desarrollador. En ese momento se inició la conversión de los Onavis a entes eminentemente financieros. Simultáneamente, en 1992, inició la operación del Programa de Fomento y Desregulación de la Vivienda (PFDV) y se reformó al artículo 27 constitucional sobre los derechos de propiedad de la tierra. Todo lo anterior impactó, como antecedente de gran relevancia, en la definición de la política habitacional en estudio.

Asimismo, la coyuntura política del contexto nacional donde se concretó esta gran estrategia habitacional se dio en el marco de dos adminis-

\footnotetext{
${ }^{10}$ En cuanto a la magnitud y localización de esta estrategia en el Estado de México, cabe comentar que la producción de conjuntos urbanos se ha ubicado casi en su totalidad en los municipios de las dos zonas metropolitanas que la entidad alberga: 269 conjuntos en la Zona Metropolitana del Valle de México, 89 en la Zona Metropolitana de Toluca y ocho en otros cinco municipios de la entidad. El total indica 355 conjuntos y más de 740 mil viviendas en el periodo 1999-2016 (Pedrotti, 2017).
} 
traciones gubernamentales sexenales (2000 a 2012) de tendencia conservadora ligadas al sector empresarial del país, el cual tuvo gran peso en la definición de varios puntos de la agenda de las políticas en general y de la política habitacional en particular.

\section{b. Proceso de toma de decisiones o modo de los estilos decisionales vigentes.}

Centralizado en el ámbito federal de gobierno a través de los Onavis, con amplia participación del sector empresarial vinculado a la actividad inmobiliaria y financiera.

En congruencia con la lógica de actuación del sector empresarial, la política habitacional transitó en su ubicación de política social a política económico-financiera. El problema de la vivienda se interpretó, a grandes rasgos, como una cuestión de ajuste de mercado - más que un problema de dificultades de acceso y de garantía de derecho para los distintos grupos sociales-, donde la oferta insuficiente requería facilitar la actuación de los sectores que pudieran ampliarla con eficiencia; y la demanda visible - para quienes pensaron la política- debía componerse de sujetos con solvencia relativa (asalariados, derechohabientes de alguno de los fondos de vivienda vinculados a su seguridad social, o bien, sujetos de crédito en la banca privada). La preocupación por el acceso a la vivienda se interpretó en buena parte como una oportunidad desde lo financiero.

c. Grado de participación de los actores politicos y sociales (locales) en el proceso de formulación e implementación de la política pública.

Baja. Se trató de una estrategia formulada desde los ámbitos centrales de decisión (gobierno federal y Onavis). El centro de la implementacióngestión de la política fue asumida por los gobiernos estatales (intermedios) en sus dependencias especializadas. Para el caso de estudio, en el Estado de México, fue la Secretaría de Desarrollo Urbano del Estado de México (Seduem).

\section{d. Distribución de costos de la misma.}

Centralizada en Onavis, Sofoles y banca privada. Para soportar el financiamiento de esta cuantiosa producción surgieron varios instrumentos financieros, tanto en la propia estructura programática de los Onavis (Infonavit, Fovissste, SHF, Fonhapo), como en otras instancias de la banca privada, la cual reanudó el otorgamiento de créditos hipotecarios, que se había visto mermado desde la crisis de mediados de los ochenta. 
Asimismo, se crearon en ese momento las Sofoles hipotecarias (Sociedades financieras de objeto limitado).

En términos de las opciones de financiamiento para las empresas promotoras, desde el ámbito público (Banobras, SHF) y privado (bancos) se instrumentaron distintas opciones de créditos puente; para la población destinataria, si bien los Onavis mantuvieron en su estructura programática el financiamiento a distintas soluciones habitacionales, los fondos se dirigieron principalmente a la adquisición de este tipo de viviendas en conjunto habitacional. Se asume incluso que los propios Onavis organizaron la demanda (Pedrotti, 2016: 245), favoreciendo la elección hacia este tipo de solución habitacional.

\section{e. Estructuración del problema y experiencias previas.}

Bajo este enfoque de política habitacional, que procuró disminuir la intervención del Estado mexicano en el desarrollo de la vivienda, se instaló en el diseño de la política un concepto que permeó desde las decisiones hasta los resultados: las "estrategias facilitadoras" (Puebla Cadena, 2002), que sin duda simplificaron el camino para la acción del sector privado (inmobiliario y financiero) en la promoción, producción y financiamiento de la vivienda. Esta visión tuvo amplia influencia también en el accionar de los Onavis.

Las acciones emprendidas homogeneizaron, normalizaron, la modalidad productiva y constructiva, así como las opciones de financiamiento en prácticamente todo el territorio nacional.

Como modalidad constructiva se optó por la producción de grandes conjuntos habitacionales de vivienda unifamiliar en prototipos idénticos, incorporando obras de urbanización, infraestructura y algunos equipamientos colectivos, según las normativas de cada estado; por su tamaño y densidad, estos conjuntos fueron comparados con la conformación territorial de una ciudad, "aunque planeada como un fraccionamiento", (Esquivel et al., 2005). En el Estado de México se le dio el estatuto jurídico de conjunto urbano con uso habitacional.

En cuanto a la modalidad productiva, todo el proceso de producción del espacio (incluyendo la gestión del suelo, la construcción de viviendas e infraestructura, la incorporación de mobiliario urbano, etc.) fue asumido por empresas inmobiliarias de diverso rango y perfil, predominaron las de alcance nacional; en la construcción de la vivienda se utilizó un sistema prefabricado a través del uso intensivo de moldes (cimbra) para el bombeo de hormigón premezclado. Este sistema ocupó insumos importados (sobre todo la cimbra) y en general no se ocupó mano de obra local en las distintas localizaciones de los conjuntos. 


\section{Variable: relaciones interinstitucionales}

a. Distribución de responsabilidades entre todas las agencias, actores involucrados y recursos de poder de cada uno y $b$. "Mapa" de relaciones interinstitucionales vitales.

En el Estado de México, la Seduem asumió de manera protagónica todo el proceso de regulación y toma de decisiones para la instalación de los conjuntos urbanos en los municipios. Se creó una Comisión interinstitucional, coordinada por la propia Seduem: la Comisión Estatal de Desarrollo Urbano y Vivienda (CEDUyV) que fungió como un "foro" técnico de análisis y consulta donde intervinieron dependencias varias del gobierno estatal (coordinadas por la Seduem) y se convocó a dependencias de los gobiernos municipales en cuestión (direcciones de Catastro, Desarrollo urbano y Obras públicas y de la Comisión de agua municipal) para decidir la autorización, previa presentación de propuesta, de construcción de un conjunto urbano en el municipio del que se tratara. Una vez autorizado por la CEDUyV, el seguimiento de la producción del conjunto corre por cuenta de la Seduem y sus direcciones, con participaciones puntuales - un tanto marginales- de los gobiernos municipales.

\section{Variable: carrera en la función pública}

Continuidad politica de los recursos humanos, existencia de incentivos apropiados.

No se relevó esta información del caso durante la ejecución del estudio que fundamenta este trabajo, por lo que no se puede incluir en este análisis.

\section{Dimensión: capacidades técnico-administrativas Nivel de análisis: entorno meso y micro-institucional Variable: organización interna}

a. Roles y distribución de funciones asignadas a cada área interna y recursos disponibles (o capacidad de planeación, gestión y recursos disponibles, o bien, tecnología-estilo de gestión interna y funciones).

Como ya se ha señalado, la decisión sobre la instalación de un conjunto urbano en un municipio mexiquense no dependió exclusiva o primordialmente de una decisión del gobierno municipal, sino de la autorización 
de la CEDUyV, órgano interinstitucional del ámbito estatal de gobierno; el municipio en cuestión participó como un actor más.

En este sentido, no hubo ni se promovieron como tal diagnósticos locales sobre la demanda habitacional existente en los municipios (tipo de población, número y composición de hogares, características socioeconómicas, etc.) ni de los recursos disponibles (suelo con vocación habitacional, agua para consumo y usos urbanos, etc.) que justificaran la instalación de conjuntos urbanos en los municipios. En otras palabras, los conjuntos urbanos no fueron planificados desde las necesidades habitacionales locales como criterio a priori.

En lo que refiere a la distribución de funciones asignadas a los gobiernos municipales en la producción de los conjuntos, cabe comentar que éstos intervinieron sólo en ciertas actividades en el marco de algunas fasesetapas definidas por la Seduem:

1) En la autorización: al formar parte de la CEDUyV contaron con voz y voto para decidir la oportuna instalación de un conjunto urbano en su ámbito jurisdiccional, aunque esta comisión interinstitucional se conformó en su mayoría, como se ha dicho, por áreas del ámbito estatal de gobierno.

2) En el seguimiento de la producción: según la normatividad establecida por la Seduem, el control técnico de las obras públicas de los conjuntos (vialidades, accesos, andadores, equipamientos educativos, áreas recreativas) es competencia del gobierno estatal, mientras que la supervisión y monitoreo de las obras privadas (viviendas) es una atribución municipal, ya que éstos otorgan las licencias de construcción. Cabe comentar que en el caso de los conjuntos urbanos, la supervisión de la calidad de las viviendas ha sido casi impracticable, por no contar con códigos de edificación o normas similares contra los cuales monitorear las construcciones, dada la modalidad del sistema constructivo (prefabricado); incluso, buena parte de los municipios donde se construyeron conjuntos no cuentan siquiera con códigos para vigilar la construcción tradicional de viviendas.

3) En la gestión post-producción (municipalización): la normatividad diseñada por la Seduem estableció que una vez concluidas las obras de urbanización y equipamiento de un conjunto urbano, el desarrollador debe dar aviso por escrito para llevar a cabo su entrega formal al municipio respectivo. Con lo anterior, la secretaría estipula el monto de la garantía que la empresa debe rendir a favor del municipio (o en ciertos casos al gobierno del estado) para responder que las obras han sido ejecutadas sin defectos ni vicios ocultos. Una vez suscrita el acta de entrega, recepción (parcial o total) de las obras, así como de las respectivas áreas de donación, el conjunto urbano se entiende incorporado al municipio 
donde se ubique, para los efectos de planeación y administración del desarrollo urbano, por lo que el gobierno municipal es, a partir de ese momento, el encargado del mantenimiento del equipamiento y las áreas comunes, así como de la prestación de los servicios. En tal sentido, al final del proceso, el municipio se ve obligado a asumir responsabilidades de mantenimiento y operación de estas áreas, cuando además, en muchas administraciones municipales no existe capacidad técnica (desde las áreas dedicadas a obras públicas) y financiera para recibir, manejar y solventar las distintas cuestiones que plantean estos espacios. De hecho, esta situación generó numerosos conflictos, sobre todo cuando se autorizaron grandes conjuntos en municipios pequeños, cuyas dimensiones superan, en superficie y población, a la mancha urbana preexistente.

b. Delimitación de los flujos de información y decisión entre las distintas subunidades y c. Formalización de la estructuración de relaciones en manuales administrativos y de procedimiento.

En el Estado de México se asistió a una modernización, a inicio de 2000, del marco regulatorio, operativo y administrativo sobre vivienda y gestión del suelo encabezado por la propia Seduem.

Específicamente, en el marco jurídico de autorización de división y fraccionamiento del suelo, y en el marco operativo-administrativo de autorización del crecimiento urbano se creó la figura del conjunto urbano.

El Libro Quinto del Código Administrativo del Estado de México fue el ordenamiento específico donde se estipularon, entre otras, las condiciones y atribuciones para la autorización, seguimiento y municipalización de los conjuntos urbanos. Específicamente con relación a la autorización de los conjuntos, la distribución de atribuciones que se estableció entre gobierno estatal y gobiernos municipales buscó conservar la injerencia del primero en el control sobre espacios y áreas a urbanizar; así, la autoridad estatal mantuvo la facultad de autorizar divisiones de suelo para conjuntos urbanos, fusiones, subdivisiones, lotificaciones para condominios, etc. A los municipios se les cedió en cambio la atribución de expedir licencias de uso de suelo y autorizar los cambios de uso, de densidad e intensidad de su aprovechamiento y de la altura máxima permitida (todas estas, funciones posteriores a las de autorización consignadas al gobierno estatal) (Gómez Ortega, 2006: 29).

El Libro Quinto cuenta con un reglamento propio, también manejado por la Seduem. Cada dirección general de la Seduem creó sus propios manuales de procedimientos para llevar a cabo las distintas actividades relativas a la autorización y seguimiento de la producción de conjuntos urbanos. No se promovió un proceso similar para las atribuciones, facul- 
tades y funciones de los municipios al respecto, sobre todo para la etapa final de recepción de los conjuntos.

d. Capacidad financiera y disponibilidad de equipamiento o de espacio físico adecuados (o bien capital-infraestructura fisica)

Baja. Como se ha comentado, los gobiernos municipales deben asumir la responsabilidad de mantenimiento del equipamiento y las áreas comunes, así como de la prestación de los servicios una vez que se entregan los conjuntos al término de las obras. Esto supone que el conjunto urbano se transforma en un área urbanizada más del municipio, para la que hay que ofrecer servicios de transporte, alumbrado público, recolección de basura, vigilancia, limpieza, mantenimiento de áreas, etc. En varios casos, estas áreas superan en tamaño y complejidad a la propia área urbana preexistente.

Desde los ámbitos federal y estatal no existe evidencia de que se hayan promovido fondos o apoyo para aumentar la capacidad financiera de los municipios con el objeto de contar con recursos (técnicos, materiales, financieros) para solventar problemas urbanos al interior de los conjuntos una vez municipalizados; por otra parte, cabe comentar que la recaudación de los municipios en relación con los conjuntos se dio en las licencias de construcción del conjunto, lo cual no resulta suficiente para la resolución de problemas infraestructurales, o bien de servicios, en el tiempo.

\section{Variable: Habilidades y conocimientos}

Nivel de información, conocimiento y habilidades básicas vinculadas a las tareas asignadas del personal responsable; capacidad de planeación, gestión y recursos disponibles; mano de obra-profesionalización.

Baja. Es sabido que las áreas destinadas al control y gestión de los asuntos urbanos de los gobiernos municipales mexiquenses no están conformadas por personal con grados de capacitación-profesionalización media o alta en la materia y que el acceso a esos cargos-puestos no proviene de una selección acorde a los criterios y requisitos necesarios para resolver los problemas que le competen.

Por otra parte, estas áreas no cuentan, en muchos casos, con códigos de construcción con los cuales vigilar y exigir la adecuada construcción de las viviendas. Menos aún de las viviendas de conjunto urbano, realizadas con procesos de prefabricación (aunque con terminaciones tradicionales). 


\subsection{El caso argentino: Programa de apoyo a la gestión local del bábitat SAM-AVE/CEVE}

Este programa surgió en el 2014 y se desarrolló hasta inicios del 2016, a partir de un convenio de trabajo colaborativo entre el Centro Experimental de la Vivienda Económica (CEVE), centro de investigación del Consejo Nacional de Investigaciones Científicas y Tecnológicas de la Nación (Conicet), Argentina, la Asociación de la Vivienda Económica (AVE), asociación civil vinculada a CEVE, y la Secretaría de Asuntos Municipales (SAM) del Ministerio de Interior y Transporte de la Nación.

El mismo no constituyó una política habitacional expresa, sino que se desarrolló como programa piloto de alcance nacional y fue desarrollado como insumo para el rediseño de políticas habitacionales vigentes. Específicamente se trabajó en municipios de diversas escalas (con énfasis en pequeños e intermedios) y provincias del país ${ }^{11}$.

Así, a diferencia del caso mexicano, éste no se trata de un programa de ejecución de unidades o mejoras habitacionales, sino de un trabajo de acompańamiento y asesoría a gobiernos municipales con el objeto de realizar estudios diagnósticos integrales de la realidad urbano-habitacional e institucional-organizacional municipal para, posteriormente, pensar y generar posibilidades de actuación local de distinta índole, bajo el formato de proyectos habitacionales específicos que se presenten a diferentes organismos estatales (provinciales) y nacionales con el fin de obtener de fondos (totales o parciales) para su ejecución.

\section{Dimensión: capacidades políticas \\ Nivel de análisis: entorno macro-institucional Variable: político-institucionales}

a. Régimen de gobierno, constitución, legislación y marcos regulatorios, reglas de juego informales

Antecedentes: El reconocimiento de la problemática habitacional como política en el país se produce durante las primeras décadas del siglo XX (1916, 1940) y específicamente desde el primer gobierno peronista (19461955). Los organismos conductores fueron históricamente el Banco Hipotecario Nacional (atención a sectores con capacidad de ahorro y necesitados de financiación a largo plazo) y el Fondo Nacional de la Vi-

\footnotetext{
${ }^{11}$ Provincia de La Rioja: municipio de Peñaloza; provincia de Corrientes: municipios de Goya y San Isidro; provincia de Chaco: municipio de Laguna Blanca; provincia de Catamarca: municipio de Belén y provincia de Mendoza: municipio de Tunuyán.
} 
vienda (Fonavi), dirigido a población de recursos insuficientes, los cuales sufrieron modificaciones en su accionar a lo largo de las décadas.

Más allá de esto, la estrategia históricamente mantenida ha sido un Estado constructor a través de sistemas centralizados de provisión de vivienda con características de obra pública y ejecución empresarial por licitación o adjudicación directa (Yujnovsky, 1984). Sólo el periodo descentralizador, en la década de los noventa, supuso traspaso de responsabilidades y ejecución de programas sin asignación de recursos o poder real a los gobiernos locales (Jiménez, 2000), que luego fueron recentralizadas a inicios del siglo XXI.

Es a partir del 2004 cuando se inicia un proceso de recentralización tras el Programa Federal de Construcción de Viviendas; sus variados subprogramas buscaron la reactivación económica, la generación de empleo genuino y el apalancamiento del crecimiento de la industria de la construcción, con la intención de impactar en el mercado laboral, la producción de insumos y, por último, en el déficit de vivienda.

Sin embargo, las intervenciones continuaron caracterizándose por la carencia de articulación con la planificación urbana y la ausencia de regulación del mercado de suelo e inmobiliario, reproducción de conjuntos de gran tamaño y "ciudades dormitorio"; crecimiento de los mercados informales, falta de consideración de los conflictos en torno al derecho a la ciudad y ausencia de incentivos a procesos de desarrollo local (Sepúlveda Ocampo, 2006 y Fernández Wagner, 2006).

La preocupación por el acceso a la vivienda se interpretó en buena parte como una oportunidad de generación de empleo e inserción laboral de sectores vinculados a la construcción, bajo la concepción viviendista por sobre la habitacional de carácter integral.

\section{b. Proceso de toma de decisiones o modo de los estilos decisionales vigentes.}

El programa analizado fue de carácter piloto y de alcance nacional, y propuesto por la Secretaría de Asuntos Municipales (SAM) del Ministerio de Interior y Transporte de la Nación; el mismo fue desarrollado como insumo para el rediseño de políticas habitacionales vigentes en provincias y municipios seleccionados por la SAM, su objetivo fue otorgar a los municipios mayores capacidades para la identificación de problemáticas y el diseño de proyectos adecuados a ella.

Se promovió una alta participación del gobierno local en la definición y el diseño de líneas de acción habitacionales pero sin revertir la tendencia histórica por la cual la alineación política entre municipio-nación o municipio-provincia (estado) resulta una condicionante importante en la obtención de fondos. 
Se reprodujo el modelo centralizado y verticalista con participación de los gobiernos locales seleccionados, a partir de criterios de alineación política con el gobierno nacional.

c. Grado de participación de los actores políticos y sociales (locales) en el proceso de formulación e implementación de la politica pública.

Alta. En contraposición al modelo de gestión tradicional históricamente desarrollado (Rodulfo, 2005), el programa supuso acompañamiento y asesoría a gobiernos municipales con el objeto de realizar estudios diagnósticos integrales de la realidad urbano-habitacional e institucional-organizacional municipal para pensar y generar proyectos habitacionales a presentar a los diferentes organismos estatales (provinciales) y nacionales, con el objetivo de obtener de fondos (totales o parciales) para su ejecución. Sin embargo cabe destacarse que el programa provino del Ministerio del Interior y no precisamente del Ministerio de Planificación Federal, del cual dependía competencialmente en el momento de su implementación, la política de vivienda del país.

\section{d. Distribución de costos de la misma.}

\section{Centralizada en organismos nacionales.}

Para la ejecución del Programa, la SAM aportó los fondos para los traslados y pago de asistencia técnica a los municipios participantes y financió algunas iniciativas de concretización de los proyectos habitacionales acordados. Los municipios sólo aportaron gastos de hospedaje del equipo técnico y refrigerios (Ministerio del Interior, Obras Públicas y Vivienda, 2014a; 2014b).

Sin embargo, el programa permitió identificar, reconocer y activar recursos locales varios existentes a capitalizarse para iniciar las estrategias de acción priorizadas (AVE-CEVE-Conicet, 2016).

\section{e. Estructuración del problema y experiencias previas.}

La mayoría de los proyectos desarrollados por los municipios involucra$\operatorname{dos}^{12}$ con anterioridad al programa respondían a una lógica viviendista bajo contratación de empresas constructoras, entregando la vivienda "llave en mano" a familias de sectores sociales medio-bajos con cierta

\footnotetext{
${ }^{12}$ El Programa SAM-CEVE contemplaba el reconocimiento y análisis de experiencias habitacionales previas de los municipios. Este reconocimiento permitió el análisis de 26 experiencias previas de los seis municipios involucrados (AVE-CEVE-Conicet, 2016).
} 
capacidad de recuperación o sectores bajos atendidos bajo subsidios que se inscribían en los registros de demanda provinciales.

Las experiencias previas relevadas manifestaban escasa voluntad de articular otros objetivos sociales, laborales y productivos, por poseer escasa incidencia local en la modalidad de aplicación de estos programas.

De igual forma, la modalidad de construcción y productiva mayoritariamente era de corte tradicional y en articulación con empresas privadas; excepcionalmente algunas de ellas (y por voluntad propia del municipio de aplicación), emplearon criterios de estímulo al desarrollo local y regional.

El Programa SAM-CEVE puso a disposición de los gobiernos locales del país - mediante jornadas de trabajo y talleres en cada localidad- herramientas para abordar la gestión local del hábitat de manera integral. Se procuró desarrollar una clara identificación de las necesidades reales a atender, un análisis particularizado de los recursos locales disponibles, la elaboración de líneas de acción factibles de ser ejecutadas desde un abordaje integral y multiactoral del hábitat, el rescate de los modos de gestión e instrumentos, los proyectos y los programas previamente desarrollados, la estructura organizacional y de los recursos existentes en el municipio y el acceso a tecnologías constructivas y de gestión apropiadas y apropiables (Ministerio del Interior, Obras Públicas y Vivienda, 2014a; 2014b).

Bajo este marco de implementación, las modalidades constructivas y productivas, así como los sectores sociales considerados en cada uno de los proyectos desarrollados bajo el programa fueron variados: tecnologías de adobe mejorado, construcción tradicional, sistemas prefabricados y diversas combinaciones de todos ellos, ejecutadas bajo modalidades varias como la autoconstrucción asistida, la articulación con emprendimientos productivos especializados, la generación de cooperativas de trabajo, la contratación a empresas locales, etc. (Ministerio del Interior, Obras Públicas y Vivienda, 2015a).

Los beneficiarios fueron los sectores bajos, medio-bajos y medios, incluyendo también a los sectores altos en líneas particulares y adaptados a las necesidades manifiestas en cada territorio a partir de una clara estratificación de la demanda y de las capacidades existentes en cada sector considerado (AVE-CEVE-Conicet, 2016). 


\section{Variable: relaciones interinstitucionales}

a. Distribución de responsabilidades entre todas las agencias, actores involucrados y recursos de poder de cada uno y b. "Mapa" de relaciones interinstitucionales vitales.

El programa brindó asistencia a municipios en Gestión Local del Hábitat en pequeños municipios de todo el país (específicamente en aquellos del Programa "Mi pueblo"13). La SAM aportó las relaciones con cada municipio, además de los recursos para llevar adelante la propuesta (viajes y honorarios del equipo asesor) y concretar algunos proyectos definidos ${ }^{14}$.

El CEVE-Conicet y AVE aportaron los equipos y saberes técnicos para las instancias de asesoramiento, capacitación y transferencia tecnológica; sistematizaron los informes integrales de las situaciones habitacionales existentes y las propuestas de abordaje y acción integral para cada municipio visitado (con presupuestos incluidos).

Los municipios afrontaron viáticos e insumos para los talleres, también proveyeron información para definir y desarrollar participativamente las líneas estratégicas. Se trabajó participativamente con todas las áreas del municipio con posibilidad de ser involucradas en iniciativas habitacionales ${ }^{15} \mathrm{y}$ se reconocieron otros actores locales a involucrar y recursos locales factibles de capitalizar.

Sin embargo, la posibilidad de ejecución de las acciones identificadas como estratégicas estuvo estrictamente vinculada a los recursos de la SAM (y otros estamentos del estado nacional) para llevarlas adelante, conforme consta en el Expediente $\mathrm{N}^{\circ}$ 51179/2015 (Ministerio del Interior, Obras Públicas y Vivienda, 2015a). La relación y dependencia municipio-nación continuó así vigente y fue de carácter vital ${ }^{16}$.

${ }^{13}$ El objetivo del Programa "Mi pueblo" era identificar y atender las necesidades de comunidades del interior del país para favorecer su fortalecimiento institucional a través de obras de infraestructura orientadas al desarrollo socioproductivo, mejoras en la conectividad y en las comunicaciones (Ministerio del Interior, Obras Públicas y Vivienda, 2015b).

${ }^{14}$ En sólo uno de los seis municipios SAM proveyó recursos y se iniciaron líneas de trabajo acordadas. En otro caso, aún sin asistencia de SAM, el municipio inició un proceso de concreción de las líneas de atención habitacional identificadas.

${ }^{15}$ Los talleres permitieron trabajar con equipos multiactorales compuestos por referentes de diferentes secretarías y direcciones (Secretaría de Desarrollo Social, Secretaría de Producción y Empleo, Secretaría de Turismo y Medio Ambiente, Secretaría de Obras Públicas, Áreas de Finanzas y Rentas, Juzgado de Faltas, etc.), también permitieron la participación de autoridades locales (intendentes, secretarios de gobierno y concejales) e integrantes de cooperativas y emprendimientos constructivos locales (AVE-CEVE-Conicet, 2016).

${ }^{16}$ Muestra de ello es que en la presentación del programa expresa que los presupuestos serán derivados sólo para la SAM, y que llegado el caso se evaluará la entrega de los mismos a los municipios. 


\section{Variable: carrera en la función pública}

a. Continuidad politica de los recursos humanos, existencia de incentivos apropiados.

No se relevó esta información del caso durante la ejecución del estudio que fundamenta este trabajo, por lo cual no se puede incluir en este análisis.

\section{Dimensión: capacidades técnico-administrativas Nivel de análisis: entorno micro-institucional Variable: organización interna}

a. Roles y distribución de funciones asignados a cada área interna y recursos disponibles (o capacidad de planeación, gestión y recursos disponibles, o bien, tecnología-estilo de gestión interna y funciones) y b. capacidad financiera y disponibilidad de equipamiento o de espacio físico adecuados (capital-infraestructura fisica).

Los municipios seleccionados por el programa, como la mayoría del país, se caracterizan por la ausencia de capacidad local para la generación de recursos propios y recuperación de plusvalías urbanas. Esto reduce en términos generales - y redujo en el programa de estudio- las capacidades de autonomía de los municipios en la concreción de líneas propias promovidas desde el Programa SAM-CEVE, las cuales hubieran permitido acciones más pertinentes a las necesidades particulares que aquéllas diseñadas centralizadamente bajo parámetros generales.

$\mathrm{Al}$ respecto, según constó en los Informes de situación municipal de cada municipio donde se trabajó con el Programa (AVE-CEVE-Conicet, 2016), se detectó que en la mayoría de los municipios no se cuenta con registros de las necesidades y demandas habitacionales locales integrales y abarcativos articulados con los registros provinciales que permitan una caracterización detallada como fase inicial del diseño de políticas más pertinentes. Se desconoce la cantidad de familias/hogares que se encuadran bajo las distintas problemáticas (especialmente aquellas cualitativas) y hay ausencia de registros sobre la propiedad de la tierra (esto supone grandes porcentajes de tierra que no poseen saneados sus títulos dominiales).

La disponibilidad de tierra urbana se resaltó también como un bien estratégico pero escaso a nivel local; escasez relacionada con la poca intervención del estado municipal en el mercado del suelo y con la poca claridad existente a nivel jurisdiccional entre municipios linderos o entre municipios y provincia, especialmente en zonas rurales o "grises". Se re- 
salta la importancia de avanzar hacia propuestas de ordenamiento territorial a nivel regional y urbano.

Operativamente, se evidenciaron dificultades en la incorporación de otras modalidades productivas diferentes a la tradicional, principalmente por falta de capacitación en aspectos relacionados con la conformación, organización y administración de las mismas. De la misma manera, la no regulación de opciones como la contratación de mano de obra local por parte de las empresas constructoras resultó ser un factor que impide la capitalización de los emprendimientos habitacionales con fines socio-laborales endógenos y de desarrollo local.

En términos de articulación intra e interinstitucional se constató el desarrollo de estructuras municipales adecuadas y consistentes, aunque con gran desarticulación entre áreas y con otros niveles de gobierno, especialmente por rivalidades político-partidarias.

Presupuestalmente los municipios manifestaron tener escasa capacidad de generar recursos tributarios y poner en práctica estrategias de recuperación por obras realizadas, por lo que dependen directamente de la coparticipación que deriva el gobierno nacional para su funcionamiento y pago de personal o gastos corrientes. Los recursos afectados al desarrollo urbano y habitacional provienen de programas provinciales y nacionales que pueden gestionarse, cuya asignación resultaba discrecional según la afinidad político partidaria existente. Esta clara dependencia planteó serias limitaciones a la hora de disponer de recursos propios para desarrollar acciones locales de hábitat y de otros temas prioritarios (salud, educación, entre otros).

b. Delimitación de los fujos de información y decisión entre las distintas subunidades y c. Formalización de la estructuración de relaciones en manuales administrativos y de procedimiento.

Los flujos de información y decisión resultaron confusos y descoordinados. En los municipios del programa no se conocían las operatorias vigentes a nivel provincial y nacional factibles de capitalizarse. La integración de las áreas municipales y la articulación interniveles gubernamentales resultaban variables ausentes, lo cual impedía tener documentaciones más completas y actualizadas y realizar en forma conjunta el diseño, ejecución y control de las obras o mejoras habitacionales.

Las relaciones no quedaron formalizadas, lo cual constituyó una debilidad importante en relación a la continuidad del programa. Ante el cambio gubernamental esta falta de institucionalización provocó efectivamente su interrupción. 


\section{Variable: habilidades y conocimientos}

a. Nivel de información, conocimiento y habilidades básicas vinculadas a las tareas asignadas del personal responsable; capacidad de planeación, gestión y recursos disponibles; mano de obra-profesionalización.

Media. Se evidenció una dotación interesante tanto de recursos humanos como de materiales y herramientas.

La disponibilidad de espacios, herramientas, maquinarias más complejas y equipos fue importante en la mayoría de los municipios del programa. Sin embargo, los municipios pequeños poseen gran cantidad de recursos humanos pero con escasa carga horaria en sus dedicaciones, nivel de especialización profesional y conocimiento experto en temáticas que facilitan procesos integrales (Informes de situación municipal de cada municipio donde se trabajó con el Programa) (Informe final del Programa presentado ante SAM-MI el 6 de enero de 2016).

\section{Breve discusión: algunas reflexiones a la luz de los casos e indicadores seleccionados}

A continuación se enlistan brevemente algunos de los hallazgos iniciales útiles para el debate. Resulta evidente que las políticas habitacionales ejecutadas en ambos países, México y Argentina, no contemplan ni consideran al gobierno local (o bien, lo hacen de manera marginal), persistiendo una preeminencia de los niveles intermedios y centrales en los procesos decisorios y de gestión, se reserva al municipio la tarea ejecutora o simplemente receptora de las políticas habitacionales.

Cuando sí lo hacen, como pudiera verse en el caso argentino, se limitan a fortalecer sus capacidades técnicas sin avanzar hacia una mejora de sus capacidades políticas o relacionales, asociadas al nivel de autonomía política y financiera (nivel de análisis macro).

Caso mexicano: al revisar las capacidades políticas resulta evidente que éstas fueron poco consideradas - menos aún capitalizadas-, ya que destaca la omisión-exclusión de su participación en el proceso de formulación de la política como tal, desconociendo en principio las características de las demandas locales (particulares, específicas de cada territorio), situación que además se legitima al normalizar-homogeneizar la modalidad constructiva y productiva de las acciones habitacionales a través de los conjuntos urbanos.

Entre las capacidades técnico-administrativas llama la atención, y hasta sorprende, la ausencia de diagnósticos previos, de acciones de apo- 
yo y fortalecimiento desde ámbitos de gobierno superiores o de los propios Onavis, tal como la carencia de instrumentos de supervisión de obras y códigos de construcción para monitorear la calidad de las viviendas en los conjuntos urbanos. El hecho de "entregar" los mismos a los municipios una vez finalizadas las obras y sin mayor apoyo en recursos financieros e instrumentales colocó a las autoridades locales en una situación de indefensión y sobreexigencia para resolver los problemas y gestionar los asuntos necesarios en esos territorios de gran escala y complejidad, en relación con su capacidad de gestión.

Existen en ese caso algunos estudios sobre los problemas urbanos, sociales, de seguridad y abasto que ha representado para los municipios la instalación de estos conjuntos (Maya Pérez y Cervantes, 2005; Eibenschutz Hartman y Goya Escobedo, 2009; Esquivel, 2006 y Esquivel y Villavicencio, 2006), aquí destacamos, sobre todo, la generación de "nuevos" problemas, a partir de su municipalización.

Caso argentino: el programa analizado permitió evidenciar, aún a pesar de su implementación a escala piloto, los recursos y capacidades de nivel meso y micro-institucional existentes en los municipios. También mostró la utilidad y los impactos que acciones simples de apoyo y fortalecimiento, desde ámbitos de gobierno superiores, pueden generar a nivel local. Estas acciones constituyen estrategias viables para contrarrestar las exigencias de alineaciones políticas con niveles superiores de gobierno, ante la falta de recursos locales para concretar los proyectos, ya que el municipio se visualiza como entidad con capacidad de generar y determinar variadas líneas de acción accesibles a los recursos locales y complementarias a la ejecución de viviendas nuevas.

La puesta en marcha de procesos locales no implicó excluir las respuestas de las instancias de gobierno superiores; no se favoreció una fragmentación territorial e institucional contraproducente, sino que se autoafirmaron las capacidades locales y se recuperaron los márgenes de autonomía que posee el espacio local y que pueden (y deben) aprovecharse, a fin de lograr la adecuación de las iniciativas a las particularidades regionales y locales, con base en proyectos de ciudad claros y construidos participativamente.

No obstante lo anterior, sorprende la reducción de los esfuerzos de apoyo a los niveles meso y micro, así como el poco avance en las propuestas que permitan modificar las reglas de juego macro en el que las acciones habitacionales se definen y ejecutan, ya que esta reducción inhibe las posibilidades de avanzar progresivamente hacia modos que superen a los netamente tradicionales y evitando ganancias en pertinencia y eficacia de las acciones. 


\section{Conclusiones}

En términos de la consideración, la capitalización y el fortalecimiento de las capacidades del municipio, en el diseño y gestión de políticas habitacionales, la atención al problema habitacional continúa siendo un eje fundamental, dado que constituye uno de los factores determinantes de la pobreza y la exclusión de grandes sectores de la población en nuestras ciudades.

Las líneas políticas tradicionalmente desarrolladas no han podido mitigar sustancialmente las situaciones deficitarias, aún más, con inversiones considerables en la materia durante las últimas décadas en América Latina, los indicadores habitacionales no han logrado disminuir de manera significativa los porcentajes históricos, esta situación reposiciona los factores de pertinencia de las acciones.

En este reposicionamiento, la incorporación y replanteo del rol del municipio en la definición y gestión de las políticas habitacionales resulta un punto de análisis y debate. Frente a ello, este trabajo se concibió como un ejercicio de análisis del involucramiento y participación de los gobiernos municipales en la definición, el diseño y la implementación de las políticas habitacionales a partir del estudio de dos casos en México y Argentina. El objetivo fue dilucidar - así como poner en cuestión- los procesos de consideración, capitalización y fortalecimiento de las capacidades de los gobiernos municipales que la implementación de los casos seleccionados promovió.

Dada la naturaleza diferente de los mismos, el abordaje no fue de carácter comparativo entre ellos, sino que los casos fueron considerados como recursos-ejemplo y fuente de aprendizaje, que esta investigación ha intentado recoger como insumos para la identificación y proposición de estrategias de mejoramiento de las políticas habitacionales vigentes.

Ahora bien, aun desde el convencimiento de la necesaria participación del gobierno municipal en la determinación de las políticas urbano-habitacionales - desde la asunción de un rol más comprometido en las decisiones- el estudio realizado evidencia que hay cuestiones que desbordan las capacidades políticas, técnicas y de gestión actuales de los poderes locales.

Sin renunciar al reconocimiento de la heterogeneidad de los municipios de las regiones, el perfil de los involucrados en los programas analizados en este trabajo se caracterizó por alineaciones políticas con los niveles superiores de gobierno, inercias burocráticas, ausencia de equipos técnicos sólidos de carrera y de planes de desarrollo urbano a nivel local, lo cual resulta una condicionante fuerte en la asunción de estas responsabilidades locales. 
Los municipios en cuestión - restringidos, por una parte, por el marco macropolítico en el que se encuentran insertos y, por otra, autolimitados a ciertas funciones de ejecución de estas y otras políticas- evidencian, como podría suceder en otros casos de la región, seguramente, la renuncia a las responsabilidades y posibilidades que les permitan resolver las problemáticas de su territorio. Desde una mirada más amplia, esta actitud pasiva parece resultar conveniente no sólo a los niveles superiores de gobierno, los cuales reproducen estructuras clientelares y verticalistas, sino a los propios gobiernos locales, dado que los exime de compromisos estratégicos a enfrentar. Así, de las numerosas debilidades en la actuación de los municipios involucrados es posible detectar capacidades existentes, pero que sin duda resultan necesarias de asumir, ampliar y fortalecer.

En este sentido, junto con una herramienta teórica metodológica construida a partir delconcepto de capacidad estatal para comprender el rol de los gobiernos municipales en materia de políticas habitacionales, este análisis también busca desmitificar cierta tendencia a la subestimación de los gobiernos locales, tanto percibidos como auto-considerados sujetos "menores", excluidos en los procesos de definición y gestión de las políticas habitacionales.

Si bien los casos analizados han permitido constatar que existen condiciones macropolíticas que inhiben las capacidades y la autonomía político-financiera municipal, existen funciones y recursos propios de este nivel -específicamente relacionadas con el desarrollo y la planificación urbana-que no son ejercidas ni puestas en funcionamiento por los mismos gobiernos locales debido a que esto supone recuperar la responsabilidad que le compete al nivel local, así como su corresponsabilidad con niveles superiores en el avance hacia una mayor consideración y fortalecimiento de sus capacidades urbanas y con ello la maduración de su rol, tanto político como técnico, en el diseño y gestión de políticas habitacionales más pertinentes.

Resulta fundamental la implementación de programas de apoyo a la consolidación de estas capacidades (a nivel macro, meso y micro), integrados complementariamente a las políticas habitacionales en curso. Esta consideración no sólo exige un replanteamiento de las políticas hoy vigentes, sino además del modo de actuación sectorizada y desarticulada de los demás ámbitos de gobierno.

Esta investigación ha permitido evidenciar que fortalecer institucionalmente a los municipios se refiere no sólo a mejorar sus capacidades técnicas (que de hecho, hoy pocos de los considerados en este estudio poseen), sino también, y fundamentalmente, sus capacidades políticas para convertirse en actores centrales que asuman sus responsabilidades en el campo de las decisiones urbano-habitacionales. Si esto no sucede, aún 
fortalecidos técnicamente, los municipios no podrán adquirir un rol protagónico en el diseño y gestión de políticas habitacionales y las políticas no podrán alcanzar los niveles de adecuación, pertinencia y efectividad que el acuciante contexto regional reclama.

Esta exigencia de consideración y fortalecimiento local se encuentra relacionada no sólo a una madurez institucional que debe ser estimulada, sino al necesario crecimiento democrático y participativo de la ciudadanía, quien debería encontrar (y reclamar), en el espacio local, el lugar privilegiado para ejercer sus derechos y obligaciones.

Existen estrategias que permitirían un progresivo empoderamiento de los municipios frente a las condicionantes macropolíticas señaladas, sólo por mencionar algunas: los programas de capacitación de los recursos técnicos, la conformación de equipos especializados articulados con otras áreas del municipio, el conocimiento y aprovechamiento de las herramientas existentes de captación de plusvalías como insumos para favorecer una mayor autonomía financiera local, el reconocimiento de los recursos locales existentes y las iniciativas factibles de desarrollar con ellos, el contar con una clara planificación urbana del territorio y el disponer de sistemas de información y de registro de las necesidades habitacionales debidamente estratificadas como insumo base para todo proceso de desarrollo urbano y habitacional, todas ellas resultan estratégicas -entre otras posibles- para el autofortalecimiento local y de crecimiento de la autonomía a partir de la conjugación de los recursos locales competitivos y económicos con estrategias de concertación social e institucional de objetivos, financiamiento y líneas de actuación.

Mientras la situacióm no se modifique y las condiciones macropolíticas no comiencen a cambiar, el posicionamiento del municipio como actor estratégico en el campo habitacional y urbano no dejará de ser una deuda pendiente en la búsqueda de soluciones superadoras a las históricamente desarrolladas en materia habitacional en la región.

\section{Fuentes consultadas}

\section{Documentos}

Ministerio del Interior, Obras Públicas y Vivienda (2014a), Expediente $\mathrm{N}^{\circ} 124678 / 2014$, Ministerio del Interior, Obras Públicas y Vivienda, Buenos Aires, Argentina, (documento interno). 
Ministerio del Interior, Obras Públicas y Vivienda (2014b), Resolución 1953/201, Ministerio del Interior, Obras Públicas y Vivienda, Buenos Aires, Argentina, (documento interno).

Ministerio del Interior, Obras Públicas y Vivienda (2015a), Expediente $\mathrm{N}^{\circ} 51179 / 2015$, Ministerio del Interior, Obras Públicas y Vivienda, Buenos Aires, Argentina, (documento interno).

Referencias

Alonso, Guillermo (2007), "Las capacidades institucionales entre el estado y la sociedad", ponencia presentada en el IV Congreso Argentino de Administración Pública, Asociación Argentina de Estudios de Administración Pública, 22-25 de agosto, Buenos Aires, Argentina.

AVE-CEVE-Conicet (Asociación de la Vivienda Económica-Centro Experimental de la Vivienda Económica-Consejo Nacional de Investigaciones Científicas y Tecnológicas de la Nación) (2016), "Informe final del Programa de apoyo para la Gestión Local de Hábitat", Secretaría de Asuntos Municipales del Ministerio Interior, Obras Públicas y Vivienda, 6 de enero, Córdoba, Argentina.

BID (Banco Interamericano de Desarrollo) (2012), Un espacio para el desarrollo: Los mercados de vivienda en América Latina y el Caribe, BID, Washington, Estados Unidos de América.

Blanco, Cid Junior (2016), "El rol de los municipios en tiempos de la Nueva Agenda Urbana en América Latina”, ponencia presentada en el Encuentro Latinoamericano. Gobiernos locales y acceso al hábitat: capacidades y desafíos para la gestión integral del hábitat, 4 de octubre, Córdoba, Argentina.

Brugué, Quim y Ricard Gomà (1998), Gobiernos locales y políticas públicas. Bienestar social, promoción económica y territorio, Ariel Ciencia Política, Barcelona, España.

Castillo Blanco, Federico (2004), Los procesos de modernización y capacitación en los gobiernos locales Iberoamericanos, Unión Iberoamericana de Municipalistas, Granada, España. 
Cepal-NU (Comisión Económica para América Latina y el Caribe-Naciones Unidas) (2016), Panorama Social de América Latina. 2015. Cepal-Naciones Unidas, Santiago de Chile, Chile, <http://repositorio.cepal.org/bitstream/handle/11362/39965/S1600175_ es.pdf? sequence $=4 \&$ isAllowed=y>, 18 de febrero de 2017 .

Cepal-Minurvi-NU (Comisión Económica para América Latina y el Caribe-Foro de Ministros y Autoridades Máximas de la Vivienda y el Urbanismo de América Latina y el Caribe-Naciones Unidas) (2016), América Latina y el Caribe. Desafíos, dilemas y compromisos de una agenda urbana común, Cepal, Santiago de Chile, Chile, <http://www.cepal.org/es/publicaciones/40656-america-latina-caribe-desafios-dilemas-compromisos-agenda-urbana-comun>, 22 de febrero de 2017.

CNV (Consejo Nacional de la Vivienda) (2017), "Planilla de viviendas y soluciones habitacionales Fonavi 1976-2014 y programas federales 2005-2014", CNV, Buenos Aires, Argentina, <http://www. cnvivienda.org.ar/viviendas.html>, 11 de marzo de 2017.

Coulomb, René (2010), "Evolución reciente y situación actual del derecho a la vivienda", en Gustavo Garza y Martha Schteingart (coords.), Tomo II. Desarrollo urbano y regional. Los grandes problemas de México, El Colegio de México, Ciudad de México, México, pp. 552-584.

Cravacuore, Daniel (2015), "Recentralización municipal en América Latina. Algunas razones explicativas", ponencia presentada en la XI Conferencia Interamericana de Alcaldes, 10 de junio, Miami, Estados Unidos de América.

Eibenschutz Hartman, Roberto y Carlos Goya Escobedo (2009), Estudio de la integración urbana y social en la expansión reciente de las ciudades en México, 1996-2006. Dimensión, características y soluciones. México, Cámara de Diputados LX legislatura-Secretaría de Desarrollo Social-Universidad Autónoma Metropolitana unidad Xochimilco-Miguel Ángel Porrúa, Ciudad de México, México.

Esquivel, María Teresa (2006), "Política habitacional y calidad de vida: impacto de los nuevos desarrollos habitacionales", en Adriana Borjas Benavente y Mónica Bucio Escobedo (coords.), La Vivienda en México: construyendo análisis y propuestas, Centro de Estudios 
Sociales y de Opinión Publica, Cámara de Diputados LIX Legislatura, Ciudad de México, México, pp. 83-104.

Esquivel, María Teresa, Esther Maya y Jorge Cervantes (2005), "La promoción privada y los grandes conjuntos habitacionales: nuevas modalidades de acceso a la vivienda”, Scripta Nova, IX (194), Universidad de Barcelona, Barcelona, España, <http://www.ub.es/ geocrit/sn/sn-194-21.htm>, 9 de abril de 2010 .

Esquivel, María Teresa y Judith Villavicencio (2006), "Características de la vivienda en México al año 2000", en Coulomb Rene y Martha Schteingart, Entre el Estado y el Mercado: La vivienda en el México de hoy, Universidad Autónoma Metropolitana unidad Azcapotzalco-Miguel Ángel Porrúa, Ciudad de México, México, pp. 51-84.

Evans, Peter (1996), "El Estado como problema y como solución”, en Peter Evans y Leandro Wolfson, Desarrollo Económico, núm. 140, Instituto de Desarrollo Económico y Social, Buenos Aires, Argentina, pp. 529-562.

Fernández Wagner, Raúl (2006), "Interrogantes sobre sustentabilidad de la política habitacional Argentina", ponencia presentada en el Seminario Iberoamericano de Ciencia y Tecnología para el Hábitat Popular-Construcción y participación del conocimiento, CEYE-Conecit-Facultad de Arquitectura de la Uiversidad Católica de Córdoba, 29 de noviembre -1 de diciembre, Córdoba, Argentina.

Gargantini, Daniela, Carolina Nievas y Verónica Greppi (2015), “Capacidades y debilidades institucionales en la gestión local del hábitat", ponencia presentada en el I Encuentro de Investigadores y Estudiantes en Ciencias Sociales y Humanidades y VI Encuentro de investigadores de la Facultad de Ciencia Política y Relaciones Internacionales, Miradas desde la diferencia: nuestras prácticas de investigación en el contexto actual, 5 y 6 de octubre, Universidad Católica de Córdoba, Córdoba, Argentina.

Global Taskforce (2016), "Declaración de la Segunda asamblea mundial de gobiernos locales y regionales en la Tercera Conferencia de la ONU sobre vivienda y desarrollo urbano sostenible-Hábitat III", The Global Network of Cities, Local and Regional Governments, 
Quito, Ecuador, <https://www.uclg.org/sites/default/files/declaracion_de_la_2a_asamblea_mundial_a_habitat_iii.pdf>, 24 de febrero de 2017.

Gómez Ortega, Martín Rolando (2006), “La formulación del Libro Quinto del Código Administrativo del Estado de México y su reglamento", tesis de licenciatura, Facultad de Arquitectura y Diseño, Universidad Autónoma del Estado de México, Toluca, México.

González Couret, Dania, Norberto Álvarez Pequeño, Odalia Águila Fleites y Deremis Pérez Aguilera (2011), "Unidades locales para la gestión integral del hábitat. Experiencia cubana”, Revista INVI, Universidad de Chile, Santiago de Chile, Chile, pp. 167-198.

Hilderbrand, Mary y Merilee Grindle (1997), "Building state capacity in the public sector. What can be done?", en Merilee Grindle, Getting good government. Capacity building in the public sectors of developing countries, Harvard University Press, Cambridge, Reino Unido, pp. 31-62.

Indec (Instituto Nacional de Estadística y Censos) (2010), Censo Nacional de Población y Vivienda, Ministerio de Hacienda de la Nación, Buenos Aires, Argentina.

Jiménez, Mabel (2000), "La política de vivienda en la Argentina: del Estado de Bienestar al estado Post-ajuste", en Mabel Jiménez, Politicas habitacionales: la situación habitacional y la politica de vivienda desarrollada en la Argentina en las dos últimas décadas, Universidad Nacional de Mar del Plata, Mar del Plata, Argentina.

Maya Pérez, Esther y Jorge Cervantes Borja (2005), La producción de vivienda del sector privado y su problemática en el municipio de Ixtapaluca, Plaza y Valdés, Ciudad de México, México.

Ministerio del Interior, Obras Públicas y Vivienda (2015b), "Programa Mi Pueblo", Ministerio del Interior, Obras Públicas y Vivienda, Buenos Aires, Argentina <https://www.mininterior.gov.ar/municipios/programa-mi-pueblo.php>, 24 de febrero de 2017.

Moreno Jaimes, Carlos (2007), "Los límites políticos de la capacidad institucional: un análisis de los gobiernos municipales en México”, 
Revista de Ciencia Política, 27 (2), Pontificia Universidad Católica de Chile, Instituto de Ciencia Política, Santiago de Chile, Chile, pp. 131-153.

Naciones Unidas (2016), "Nueva Agenda Urbana. Resolución aprobada por la Asamblea General el 23 de diciembre de 2016", ONUHabitat, Quito, Ecuador, <http://habitat3.org/wp-content/ uploads/New-Urban-Agenda-GA-Adopted-68th-Plenary-N1646660-S.pdf>, 24 de febrero de 2017.

Oszlak, Oscar y Edgardo Orellana (2001), El análisis de la capacidad institucional: aplicación de la metodología SADCI, mimeo, Buenos Aires, Argentina, <http://www.oscaroszlak.org.ar/images/articulosespanol/OSZLAK\%20Oscar\%20y\%20ORELLANA\%20 Edgardo\%20\%20El\%20analisis\%2de\%20la\%20capacidad\%20 institucional.pdf>, 27 de julio de 2017.

Pedrotti, Carolina (2017), "Producción y gestión del espacio residencial en la vivienda social promovida por el sector privado", proyecto de investigación, El Colegio Mexiquense, A. C., Toluca, México.

Pedrotti, Carolina (2016), Calidad residencial y condiciones de producción en la vivienda social promovida por el sector privado. Zona Metropolitana de Toluca, 2001-2011, Programa Universitario de Estudios sobre la Ciudad/UNAM-Instituto del Fondo Nacional de la Vivienda para los Trabajadores, Ciudad de México, México.

Puebla Cadena, Claudia (2002), Del intervencionismo estatal a las estrategias facilitadoras: los cambios en la política de vivienda en México, (1972-1994), El Colegio de México, Ciudad de México, México.

Rodulfo, María Beatriz (2005), “La evolución de la gestión en políticas habitacionales y su relación con el desarrollo local. El caso argentino. Análisis comparativo de modelos de gestión”, exposición en el XI Encuentro de la Red ULACAV: Universidad y Vivienda Social-Experiencias Académicas para la Gestión Local del Hábitat, Universidad Nacional de Rosario, 29 de septiembre-1 de octubre, Rosario, Argentina.

Rosas Huerta, Angélica (2008), "Una ruta metodológica para evaluar la capacidad institucional”, Politica y Cultura, núm. 30, Universidad 
Autónoma Metropolitana unidad Xochimilco, Ciudad de México, México, pp. 119-134.

Scartascini, Carlos y Mariano Tommassi (2014), Capacidades gubernamentales en América Latina: Por qué son tan importantes, qué se sabe sobre ellas y cuáles son los pasos a seguir, BID, Washington, Estados Unidos de América.

Schteingart, Martha (1989), Los productores del espacio habitable. Estado, empresa y sociedad en la Ciudad de México, El Colegio de México, Ciudad de México, México

Sepúlveda Ocampo, Rubén y Raúl Fernández Wagner (2006), Un análisis crítico de las politicas nacionales de vivienda en América Latina, Centro Cooperativo Sueco, San José, Costa Rica.

Sikkink, Kathryn (1991), Ideas and institutions: developmentalism in Brazil and Argentina, Cornell University Press, Ithaca, Nueva York, Estados Unidos de América.

Sikkink, Kathryn (1993), "Las capacidades y la autonomía del estado en Brasil y Argentina. Un enfoque neoinstitucionalista", Desarrollo Económico, 32 (128), Instituto de Desarrollo Económico y Social, Buenos Aires, Argentina.

UCLG-CGLU (Red Mundial de Ciudades y Gobiernos Locales y Regionales-United Cities and Local Governments) (2016), "El compromiso de Bogotá y la agenda de acción", Declaración del $5^{\circ}$ Congreso de CGLU. Cumbre Mundial de Líderes Locales y Regionales, 15 octubre, Bogotá, Colombia, <https://www.uclg. org/sites/default/files/el_compromiso_de_bogota_0.pdf $2,24 \mathrm{de}$ febrero de 2017.

UNAM (Universidad Nacional Autónoma de México) (2013), México. Perfil del sector de la vivienda. Coordinación de Humanidades, Programa Universitario de Estudios sobre la Ciudad/UNAMComisión Nacional de Vivienda-Hábitat/ONU, Ciudad de México, México.

Villar, Alejandro (2002), "Funciones, competencias y tecnologías en el gobierno local. Un análisis del Banco de Experiencias Locales", en Daniel Cravacuore (comp.), Innovación en la gestión municipal, 
Federación Argentina de Municipios-Universidad Nacional de Quilmes, Buenos Aires, Argentina, pp. 69-85

Yujnovsky, Oscar (1984), Claves politicas del problema habitacional argentino 1955-1981, Grupo Editor Latinoamericano, Buenos Aires, Argentina.

Recibido: 31 de julio de 2017. Reenviado: 11 de octubre de 2017. Aceptado: 27 de noviembre de 2017.

Daniela Mariana Gargantini. Doctora en Arquitectura y posdoctoranda de la Universidad Nacional de Rosario, Argentina. Investigadora adjunta del Consejo Nacional de Investigaciones Científicas y Tecnológicas de Argentina en el Centro Experimental de la Vivienda Económica. Docente-investigadora de la Universidad Católica de Córdoba, Argentina. Su línea de investigación actual es Municipios y acceso al hábitat: condiciones y capacidades institucionales para la gestión local e integral del hábitat. Entre sus últimas publicaciones destacan: "Sistemas locales de registro de demanda habitacional y formulación de políticas habitacionales en municipios argentinos: caracterización y relaciones", en Alicia Ziccardi y Daniel Cravacuore (coords.), Los gobiernos locales y las politicas de vivienda en México y América Latina, Programa Universitario de Estudios sobre la Ciudad/Universidad Nacional Autónoma de México, Ciudad de México, México, pp. 161-184 (2017); Tierra de conflictos. Conflictos urbanos y violaciones al derecho a la ciudad en Córdoba capital, Editorial de la Universidad Católica de Córdoba, Córdoba, Argentina (2016); “The experimental centre of economic housing", en Rajesh Tandon, Budd Hall, Walter Lepore y Wafa Singh (edits.), Knowledge and engagement. building capacity for the next generation of community based researchers, E-handbook, Unesco Chair and the Library of the University of Victoria, Victoria, Canadá, pp. 90-97 (2016); "Metodología de evaluación de los sistemas locales de registro de la demanda habitacional”, Revista Studia Politicae, núm. 35, Facultad de Ciencia Política y Relaciones Internacionales, Universidad Católica de Córdoba, Córdoba, Argentina, pp. 59-89 (2016).

Carolina Inés Pedrotti. Doctora en Urbanismo por la Universidad Nacional Autónoma de México. Profesora-investigadora de El Colegio Mexiquense, A. C., donde además se desempeña como coordinadora de la Maestría en Ciencias Sociales con especialidad en Desarrollo Municipal. Es docente en la Facultad de Arquitectura y Diseño de la Universidad Autónoma del Estado de México, en la licenciatura en Administración y 
Promoción de la Obra Urbana. Sus líneas de investigación actual son las políticas habitacionales en México y su implementación en el ámbito local. Entre sus más recientes publicaciones destacan: "La gestión de la política habitacional en el Estado de México para la producción de conjuntos urbanos", en Alicia Ziccardi y Daniel Cravacuore (coords.), Los gobiernos locales y las políticas de vivienda en México y América Latina, Programa Universitario de Estudios sobre la Ciudad/Universidad Nacional Autónoma de México, Ciudad de México, México, pp. 47-71 (2017); Calidad residencial y condiciones de producción en la vivienda social promovida por el sector privado. Zona Metropolitana de Toluca, 2001-2011, Programa Universitario de Estudios sobre la Ciudad/Universidad Nacional Autónoma de México-Instituto del Fondo de la Vivienda para los Trabajadores, Ciudad de México, México (2016), "Problemas y propuestas sobre el suelo urbano en el debate iberoamericano", en Alfonso Iracheta, Carolina Pedrotti y Raúl Fernández Wagner (coords.), El suelo urbano en Iberoamérica: crisis y perspectivas, El Colegio Mexiquense, A. C, Toluca, México, pp. 503-507 (2014). 